\title{
DISCURSOS FASCISTAS: ENFRENTAMENTO, RESISTÊNCIA E COMBATE NA/PELA LÍNGUA(GEM)
}

\author{
Danie Marcelo de JESUS \\ Universidade Federal do Mato Grosso \\ daniepuc@gmail.com \\ Leina Cláudia Viana JUCÁ \\ Universidade Federal de Ouro Preto \\ leinajuca@gmail.com \\ https://orcid.org/0000-0002-4325-9536
}

Nos últimos anos, tornou-se facilmente perceptível a ampliação de discursos considerados neofascistas circulando em nossa sociedade, particularmente por meio das mídias digitais. As consequências desses discursos são profundas para a democracia brasileira, que se vê ameaçada por ações que variam desde perseguições políticas até falácias que forjam informações científicas, tornando-as incorretas e imprecisas. Além disso, tornou-se facilmente identificável a construção e a propagação de projetos de necropolítica que atingem as populações mais vulneráveis, ampliando diferentes formas de violência simbólica e/ou física. Diante desse quadro, como docentes de universidades públicas brasileiras, pesquisadores e linguistas aplicados engajados em reflexões e discussões acerca das relações que se estabelecem entre língua(gem) e construção social e identitária, nos preocupamos e nos sentimos não apenas provocados a, mas também responsáveis por construir formas e práticas de resistências. Este dossiê resulta dessa preocupação, dessa provocação e dessa responsabilidade.

Os trabalhos que desfilam neste dossiê são caracterizados como artigos de opinião e não seguem, portanto, o formato tradicional de artigos normalmente publicados nas revistas, livros e periódicos das áreas de Letras, Linguística Aplicada e/ou Linguística. 
Essa escolha levou em consideração, dentre outras coisas, a urgência por respostas imediatas aos discursos fascistas que nos invadem e nos assombram, inclusive em tempos de pandemia. Portanto, optamos por prescindir de estudos mais detalhados, que poderiam requerer maior tempo de desenvolvimento, uma vez que compreendemos que a situação atual não nos permite esperar, exigindo respostas e posicionamentos imediatos. Além de espaço aberto para o enfrentamento aos discursos fascistas e para a tomada de posição dos/das colegas que participam deste dossiê, esperamos que ele sirva, ainda, de inspiração e auxílio àqueles/àquelas que, também preocupados/preocupadas com o quadro que se apresenta atualmente no país, sentem o desejo e a necessidade de problematizá-lo. Que este dossiê possa alcançar espaços variados, as ruas, as escolas, as universidades, as mesas em torno das quais nos sentamos para discutir nossas existências.

É nesse sentido, portanto, que os diferentes artigos de opinião aqui publicados trazem reflexões em torno das relações entre língua(gem), política, pandemia, educação, cultura, história e sociedade, apresentando posicionamentos no enfrentamento aos discursos fascistas que ora se impõem sobre nós, quer seja realizando análises desses discursos, ou ensinando como percebê-los; quer seja evidenciando suas consequências para as vidas de todos nós, ou sugerindo estratégias de resistência e combate, mostrando possibilidades discursivas para a construção de outras formas de compreensão de mundo e de possibilidades de (co)existência. Por fim, os artigos também contribuem para a ampliação e o aprofundamento de discussões em torno de variados temas, relacionando língua(gem) e política, violência, direitos civis, direitos humanos, autoritarismo, lutas de classe e de identidades, dentre outros.

O dossiê se inicia com um bate-papo entre Lynn Mario Trindade Menezes de Souza (USP) e Walkyria Monte Mor (USP), intitulado "É proibido proibir: Ambiguidades e Enfrentamentos na/pela Linguagem", que traz reflexões dos autores sobre suas experiências de vida e acadêmicas e as fissuras que, ao longo de suas carreiras, foram identificando e procurando utilizar no enfrentamento das tradições e das desigualdades sociais no Brasil, valendo-se particularmente de atitudes subversivas frente aos discursos fascistas, que ora procuram reflorescer e se reinventar no país do governo Bolsonaro.

O primeiro artigo, intitulado "In Memoriam: História, Memória e Pós-Memória no Brasil de Hoje", de Andréa Machado de Almeida Mattos (UFMG), propõe uma discussão 
- por meio do conceito de memória e pós-memória - sobre os contornos do discurso fascista e autoritário no Brasil.

No segundo artigo, “A Terra Plana é aqui”, Roberto Bezerra (UFRJ) reflete ironicamente em torno da ideia terraplanista sobre a constituição do planeta, evidenciando seu caráter falacioso e suas implicações sociais e políticas, e problematizando a necessidade de nos educarmos para o diálogo em meio ao dissenso cotidiano em que vivemos.

No terceiro artigo, “Não podemos fazer do Brasil a casa da mãe Joana': uma perspectiva de resistência para políticas migratórias da extrema direita”, Leandro Rodrigues Alves Diniz (UFMG) e Ana Cecília Cossi Bizon (UNICAMP) problematizam a questão do discurso nacionalista e xenofóbico que caracteriza a atual política externa brasileira cujas práticas acabam promovendo o desprezo à história e à dor do outro.

Em “Navegar em ondas fascistas não é preciso!", o quarto artigo aqui apresentado, Marco Antônio Margarido Costa (UFCG) problematiza a questão do discurso fascista com base no documentário \#AnneFrank: vidas paralelas em diálogo com os estudos de Pêcheux. Em seu texto, Costa chama atenção para a necessidade de formular práticas de resistência frente ao discurso de violência propagado pelo atual governo brasileiro.

No quinto artigo, "Do mundo do esporte ao dia-a-dia numa pandemia: precisamos falar sobre fascismo", Ana Karina de Oliveira Nascimento (UFS) e Laudo Natel do Nascimento (UFAL/USP) discorrem sobre atitudes de repúdio ao racismo feitas por alguns esportistas e as críticas que afirmam que no esporte não há lugar para atitudes políticas. Esse pano de fundo é utilizado para refletir sobre como os discursos fascistas vão sendo apresentados e absorvidos no cotidiano das pessoas.

Em "O discurso fascista e suas implicações para a educação dos povos do campo e indígenas", o sexto artigo do dossiê, Luiz Otávio Costa Marques (UFVJM) e Paulo Afranio Sant'Anna (UFVJM) têm como objetivo refletir sobre enunciados fascistas e seu impacto nas políticas públicas educacionais voltadas para povos do campo e indígenas no Brasil, evidenciando as consequências sociais de tais enunciados e os possíveis contradiscursos e estratégias de resistência ao combate de narrativas discriminatórias.

Wagner Rodrigues Silva (UFT), no sétimo artigo, "Conveniência da ciência na política brasileira de alfabetização", apresenta uma análise das consequências de discursos 
fascistas na política nacional de alfabetização, discursos esses que se valem de falácias científicas como subsídios para justificar alterações na educação pública brasileira.

No oitavo artigo, "Mostre suas garras e solte suas feras: haverá sempre um artista para te criticar", Vera Lúcia Menezes de Oliveira e Paiva (UFMG) reflete sobre a charge de Renato Aroeira, que faz uma crítica ao presidente Bolsonaro demonstrando atitude de resistência em relação ao autoritarismo de seu governo.

No nono artigo, "A incômoda representabilidade da figurabilidade expulsa abjeta, mas não aniquilada", Rubra Araújo (UFT) aborda a questão das figuras abjetas e marginalizadas no contexto contemporâneo e seus efeitos sociais e políticos.

Em "Falemos de gênero pelo bem de nossas meninas", o décimo artigo deste dossiê, Martha Júlia Martins (UFRR) aponta para a necessidade de reflexão sobre a confusão que tem sido feita entre estudos de gênero e ideologia de gênero e processos de opressão do governo bolsonarista.

No décimo primeiro artigo, "Do 'rosa e azul' ao 'elas não se depilam": nuances do feminino no atual governo brasileiro", Simone Batista da Silva (UFRRJ) e Andréa Cotrim Silva (IFSP/USP) nos conduzem a uma reflexão sobre o lugar que a figura feminina tende a tradicionalmente ocupar em um governo conservador.

No décimo segundo artigo, "Existir e re-existir: as comunidades LGBTQIA+ sob ataque no Brasil de 2020”, Daniel Ferraz (USP) e Lucas Miquelon (USP) problematizam a questão da educação linguística e da formação de professores e de professoras e sua confluência com as questões LGBTQIA+.

Ana Vilacy Galucio (MCTI), no décimo terceiro artigo, "Línguas silenciadas, nenhuma a mais!", nos convida a pensar os efeitos da COVID-19 sobre os povos da terra, a ampliação da política de morte praticada pelo atual governo e as enormes perdas que a humanidade sofre com o desaparecimento de povos originários, de suas histórias e de seus saberes.

Em “Depois da Pandemia e do Pandemônio: Linguística Aplicada e Antirracismo", o décimo quarto artigo deste dossiê, Miriam Jorge (University of Missouri St. Louis) e Mara Barbosa (Texas A\&M University-Corpus Christi) nos mostram a necessidade de questionar o aprofundamento das desigualdades sociais e raciais causado pelo governo bolsonarista. 
Cláudia Hilsdorf Rocha (UNICAMP), no décimo quinto artigo, “"Escute com seu corpo': o potencial subversivo do afeto em tempos sombrios", aponta a micropolítica dos afetos como estratégica de resistência e subversão ao novo fascismo que irrompe brutalmente nos tempos sombrios contemporâneos.

Em "Do tecido da vida, do puído do vírus: sobre crianças, novelos e linhas", o décimo sexto artigo deste dossiê, Ana Paula Duboc (USP) opta por jogar holofotes sobre sujeitos da infância e a violência que sofrem quando roubados de seu direito de ser criança no atual cenário fascista brasileiro.

Encerrando nosso dossiê, Francesca Dell'Olio (Università di Padova/USP) nos presenteia com uma análise do bolsonarismo que facilita a identificação fascista do atual governo brasileiro e, ao mesmo tempo, evidencia sua desestruturação política e ideológica, o que permite ações de dissenso e de solidariedade, ou seja, abre espaço para a esperança.

Tomados pela necessidade e também pela possibilidade de nos reesperançarmos, reafirmamos, portanto, nosso desejo de, nossa responsabilidade por e nosso engajamento nas lutas pelo direito de todo ser humano a uma (co)existência justa e pacífica e desejamos a todes uma ótima leitura! Que sigamos sempre juntes ${ }^{1}$ !

Danie Marcelo de Jesus e Leina Jucá Organizadores

\footnotetext{
${ }^{1}$ Em vista do momento político que vivemos no Brasil na atualidade, faz-se necessário pontuar o receio que pode causar a tomada pública de posicionamentos críticos frente a determinados discursos e ações (ou a falta delas) do poder público. Contudo, como profissionais eticamente comprometidos com o bem público, a serviço da sociedade brasileira por meio da ciência, da pesquisa e da educação, não poderíamos nos refutar a essa tarefa, ainda que, de certa forma, "perigosa". Assim, gostaríamos de externar nossos profundos agradecimentos à equipe editorial da Revista X, que prontamente acolheu nossa proposta e possibilitou esta publicação, e às/aos colegas que, corajosamente, por meio de seus artigos, ergueram suas vozes no enfrentamento aos discursos fascistas que ora insistem em se reinventar e brutalizar nossas existências. Agradecemos a todes pela preciosa parceria!
} 